\title{
Construction of Virtual Neuron and Consolidation of Sleep and Memory Process- A Molecular Docking and Biomathematical Approach
}

\author{
Bin Zhao ${ }^{1 *}$, Kuiyun Huang ${ }^{1}$, Jinming $\mathrm{Cao}^{2}$, Xia Jiang ${ }^{3}$ and Jingfeng Tang ${ }^{4}$ \\ ${ }^{1}$ Department of Mathematics, School of Science, Hubei University of Technology, China \\ ${ }^{2}$ School of Information and Mathematics, Yangtze University, Hubei, China \\ ${ }^{3}$ Hospital, Hubei University of Technology, Wuhan, Hubei, China \\ ${ }^{4}$ National "111" Center for Cellular Regulation and Molecular Pharmaceutics, Hubei University of Technology, China
}

*Corresponding author: Bin Zhao, School of Science, Hubei University of Technology, China.

Received Date: March 09, 2019

Published Date: April 15, 2019

\begin{abstract}
Sleep plays an important role in learning and memory processing in our daily life. There is also a direct correlation to insufficient sleep increasing the risk of diabetes. As sleep can be broadly divided into SWS sleep and REM sleep within a SWS_REM cycle, this paper presents a literature review aiming to firstly summary the sequential contributions of these two kinds of sleep on declarative and procedural memory consolidation and then explain the neurobiological root of memory impairment under sleep deprivation. An attempt was made to formulate some mathematical models on neuron of sleep and memory process which are the important physiological phenomena of human beings. We find out that Nervousness, Age and Sex have great influence on sleep and memory quality, among which Nervousness has the strongest influence on sleep and memory quality. As a stepping stone in this direction, the present study is designed with a molecular docking and biomathematical approach to formulate some speculations to construct virtual neuron and consolidation of sleep and memory process.
\end{abstract}

Keywords: Virtual neuron; Two-stage model; SWS sleep; REM sleep; Memory consolidation; Sleep deprivation

\section{Introduction}

The relationship between sleep and memory never fails to fascinate human beings as we always keep curious about how the memory form and consolidate [1]. Nevertheless, recent developments in molecular genetics, neurophysiology, and the cognitive neurosciences have produced a striking body of research that provides converging evidence for an important role of sleep in learning and the reprocessing of memories. Also, sleep deprivation has become a prevalent public health epidemic with a wide range of harmful consequences, including memory and cognitive impairment [2], some scientists tend to focus attention on the neurobiological root of this universal human experience.

\section{Previous Work}

Effects of sleep stage on consolidation early study of different sleep stages in memory consolidation in rats mainly focused on
REM sleep (Random Eye Movement sleep) and the consequences of REMD (REM sleep deprivation) by repeatedly waking subjects at the first signs of REM sleep. All these memory tasks were typically emotionally loaded as it has been proved that REM sleep priority to improve the consolidation of memory emotions $[3,4]$, and it turned out that REMD is only valid for a specific period of time after learning — the so-called "REM sleep window" $[5,6]$.

The first evidence of the causal role of SWS (Slow Wave Sleep) reactivation during memory consolidation comes from the study of human spatial location in the presence of odor [7]. Reactivation activates hippocampal memory redistribution to new cortical storage locations. On the other hand, another hypothesis, named 'sequential hypothesis', which argues that the best benefit of sleep for consolidating declarative and non-declarative memory occurs when SWS and REM sleep occur one after the other is also verified 
by the cross effect of SWS/REM on declarative/procedural memory consolidation $[8,9]$.

\section{The Effects of Sleep/Sleep Deprivation on Memory}

\section{Sleep's promotion on memory consolidation}

Sleep is characterized by the rapid occurrence of REM sleep and non-REM sleep, including slow wave sleep (SWS, Phases 3 and 4) and light sleep Phases 1 and 2 (see Figure 1, part a). In humans, the first part of the night (early sleep) is characterized by a high amount of SWS, while REM sleep is dominant in the lower half (late sleep). SWS and REM sleep are characterized by a specific pattern of electric field potential oscillations (see Figure 1, part b) (Figure 1).
In subsequent rapid eye movement (REM) sleep, the brain system operates in a "separated" mode, which is also associated with separation between long-term and temporary storage. This enables a synaptic consolidation of the local encapsulation process, which reinforces the memory characterization of system integration during previous SWS (thick line). In general, memory gets the best results from slow wave sleep and rapid eye movement sleep. However, due to their different characteristics, integrated declarative memory (which combines the characteristics of different memories in different memory systems) theoretically benefits more from SWS-related system integration, with specific and discrete procedural memory benefits more from REM sleep - associated synapse consolidation in the local brain circuit [10] (Figure 2).

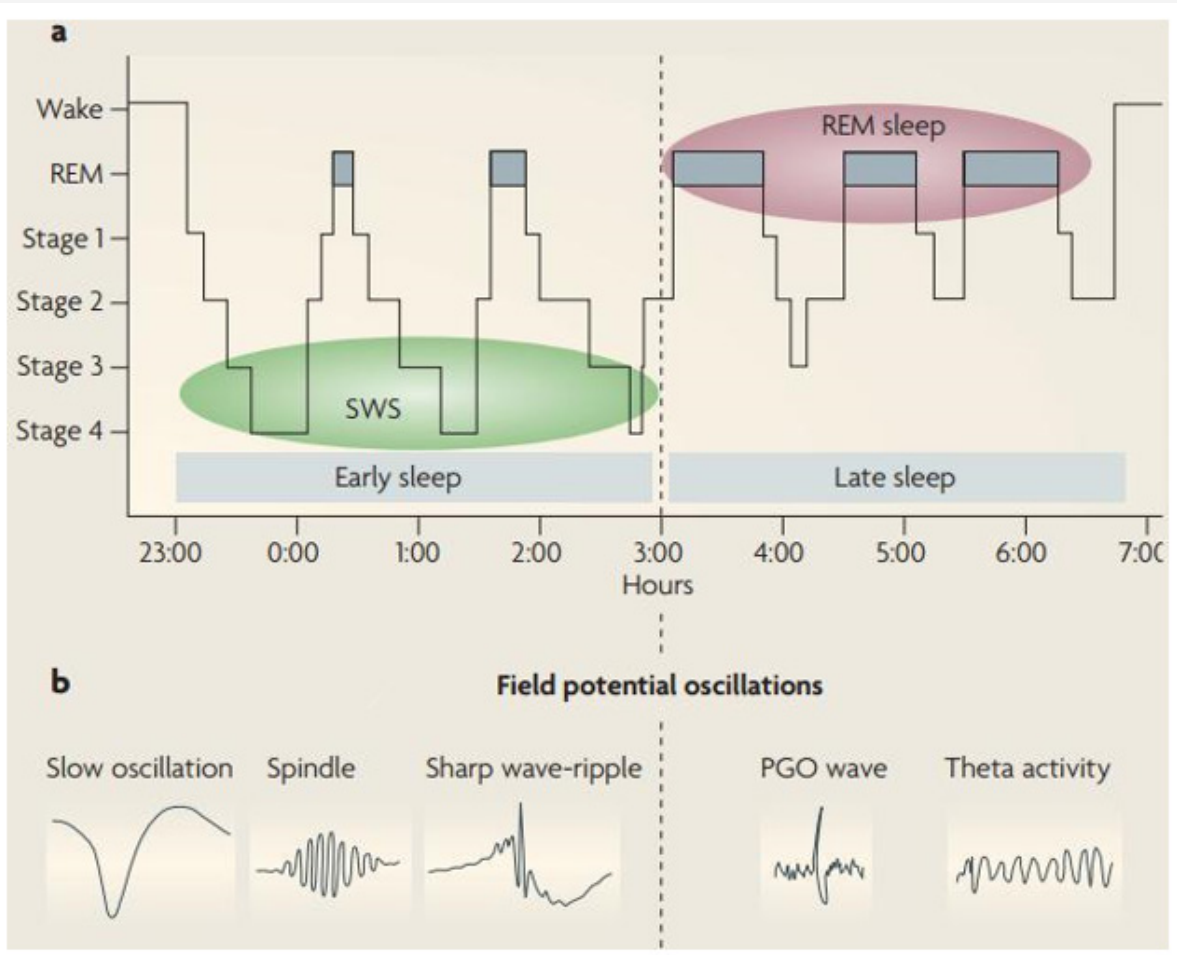

Figure 1: Effect of diameter-to-thickness ratio on stress.

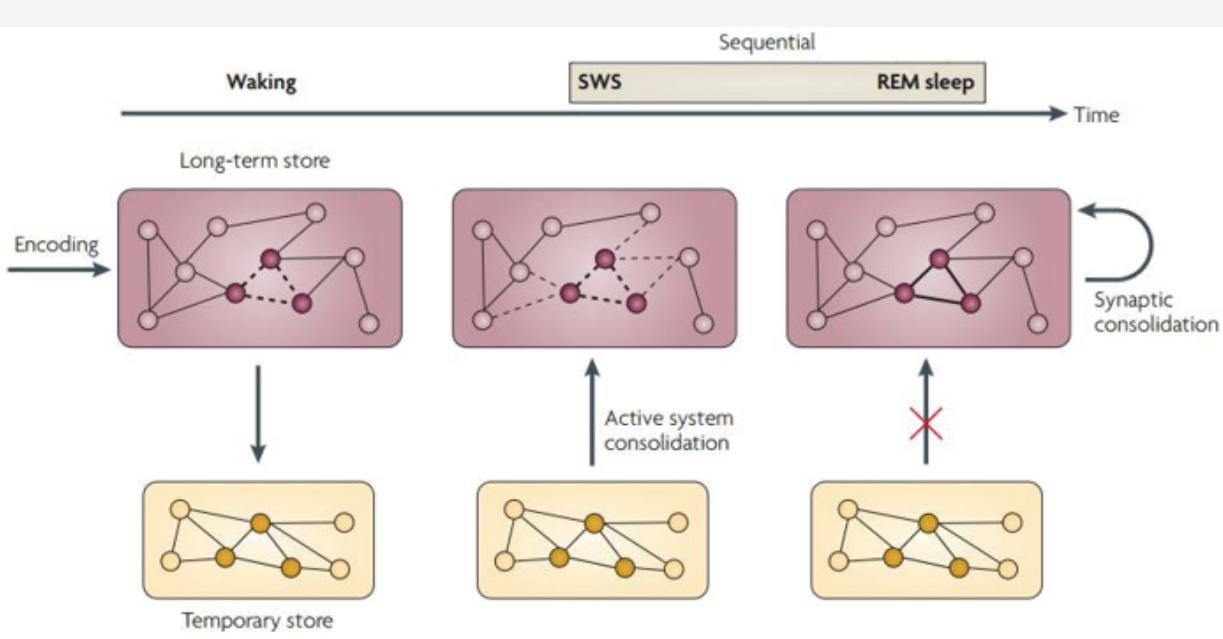

Figure 2: Sequential contributions of SWS and REM sleep on memory consolidation. 


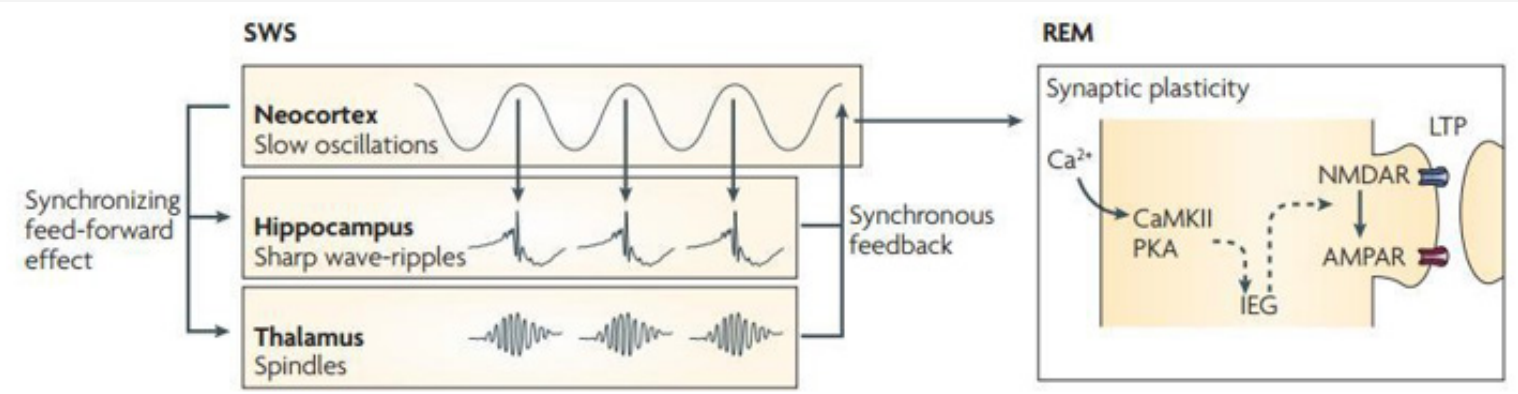

Figure 3: System consolidation hypothesis.

There are currently two hypotheses that explain the mechanism of memory consolidation during sleep. Synaptic homeostasis hypothesis [11] is a by-product of the overall synaptic reduction that occurs during sleep. The active system consolidation hypothesis suggests that the active consolidation process is caused by selective reactivation of memory in sleep [12]. The former use is to serve a global downscale of synaptic strength by the slow oscillations to achieve sustainable levels in energy and tissue volume requirements and allow for the repetitive use of synapses in future coding, and the process of the latter can be depicted $[13,14]$. Therefore, we have the two-stage model and sequential contributions of SWS and REM sleep on memory consolidation (Figure 3).

\section{Memory impairment after sleep deprivation}

Marion and his colleagues once used electrophysiological, molecular and behavioural indices to non-invasively study LTP-like plasticity in humans after sleep and sleep deprivation. The outcome

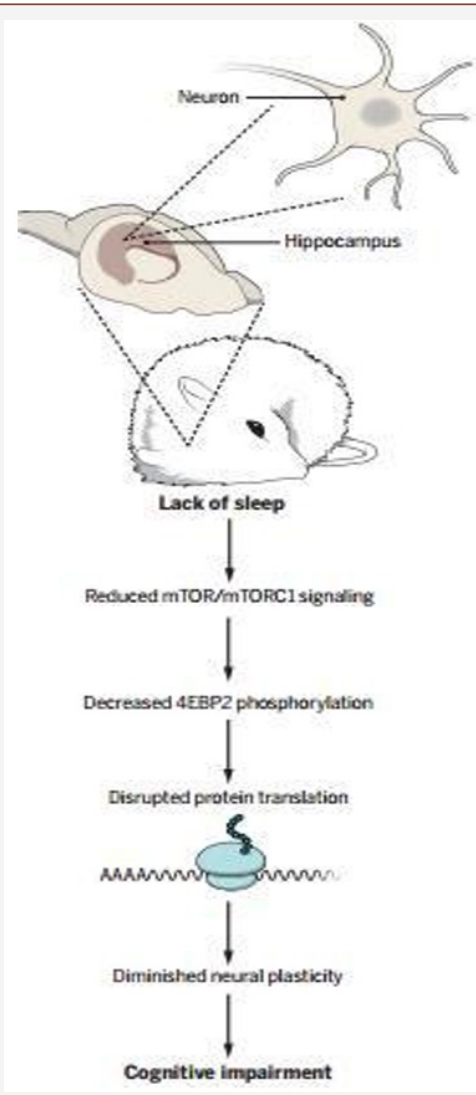

Figure 4: Effects of sleep deprivation on protein synthesis procedure. shows that LTP-like plasticity decreases after sleep deprivation verified by declined MEP amplitudes, lower potential modulator level and less correctly recalled word-pairs during the declarative memory task [15]. For further studying, Tudor et al extended that 5 hours of sleep loss attenuated both mTORC1-mediated phosphorylation of 4EBP2 and the interaction between eukaryotic initiation factor 4E (eIF4E) and eIF4G in the hippocampi of sleepdeprived mice using an in vivo protein translation assay. What is more, by increasing the abundance of 4EBP2 in hippocampal excitatory neurons before sleep deprivation the abundance of phosphorylated 4EBP2 increased, and the amount of eIF4EeIF4G interaction restored and hippocampal protein synthesis to that seen in mice that were not sleep-deprived and prevented the hippocampus-dependent memory deficits associated with sleep loss [16]. Effects of sleep deprivation on protein synthesis procedure is also verified [17] (Figure 4).

And the molecular neurobiology mechanism of sleep on protein synthesis procedure is also verified [18]. Next, we consider the neuronal functions in sleep and memory consolidation process by the following fractional-order differential equations:

$$
\left\{\begin{array}{c}
\frac{d^{\alpha_{1}} x_{1}}{d t^{\alpha_{1}}}=\alpha\left(x_{2}-x_{1}\right)+x_{4} \\
\frac{d^{\alpha_{2}} x_{2}}{d t^{\alpha_{2}}}=h x_{1}-x_{1} x_{3}+c x_{2} \\
\frac{d^{\alpha_{3}} x_{3}}{d t^{\alpha_{3}}}=x_{1} x_{2}-b x_{3} \\
\frac{d^{\alpha_{3}} x_{3}}{d t^{\alpha_{3}}}=x_{2} x_{3}+r x_{4}
\end{array}\right.
$$

where $0<i<1,(i=1,2,3,4)$ is a parameter describing the order of the system in sleep and memory consolidation process, $x_{i}(i=1,2,3,4)$ is the anti-synchronization function of the time $t$. If $a=35, b=3, c=12$, $\mathrm{h}=7,0.085 \leq \mathrm{r} \leq 0.798$, then the system is in a chaotic state.

Suppose that some ractional-order differential equations are response systems of the neuronal functions in sleep and memory consolidation process:

$$
\left\{\begin{array}{c}
u_{1}(t)=-D_{t}^{\beta_{1}} x_{1}-D_{t}^{\alpha_{1}} x_{1}-\left(\hat{\alpha}\left(y_{2}-y_{1}\right)+y_{4}\right)+\hat{\alpha}\left(x_{2}-x_{1}\right)+x_{4}-k_{1} e_{1} \\
u_{2}(t)=-D_{t}^{\beta_{2}} x_{2}-D_{t}^{\alpha_{2}} x_{2}-\left(\hat{h}\left(y_{1}-y_{1} y_{3}+\widehat{c} y_{2}\right)\right)+\hat{h} x_{1}-x_{1} x_{3}+\widehat{c} x_{2}-k_{2} e_{2} \\
u_{3}(t)=-D_{t}^{\beta_{3}} x_{2}-D_{t}^{\alpha_{3}} x_{2}-\left(y_{1} y_{2}-\widehat{b} y_{3}\right)+x_{1} x_{2}+\widehat{b} x_{3}-k_{3} e_{3} \\
u_{4}(t)=-D_{t}^{\beta_{4}} x_{2}-D_{t}^{\alpha_{4}} x_{2}-\left(y_{2} y_{3}-\widehat{r} y_{4}\right)+x_{2} x_{3}+\widehat{r} x_{3}-k_{4} e_{4}
\end{array}\right.
$$


where $\hat{a}, \hat{b}, \hat{c}, \hat{h}, \hat{r}$ are the estimated values of the parameters a, b, c, h, r on the system (3.1) respectively; and $0<\beta_{i}<1,(i=1,2,3,4)$ is a parameter describing the order of the system (3.2); $d^{q} / d t^{q}=D_{t}^{q}, \mathrm{q}=\alpha_{\mathrm{i}^{\prime}}, \beta_{\mathrm{i}^{\prime}}(\mathrm{i}=1,2,3,4)$ are the sleeping time in the Caputo sense, and $\mathrm{x}=\left(\mathrm{x}_{1}(\mathrm{t}), \mathrm{x}_{2}(\mathrm{t}), \mathrm{x}_{3}(\mathrm{t}), \mathrm{x}_{4}(\mathrm{t})\right)^{\mathrm{T}}, \mathrm{y}=\left(\mathrm{y}_{1}(\mathrm{t})\right.$, $\left.y_{2}(t), y_{3}(t), y_{4}(t)\right)^{T}$ are the status vectors of system (3.1) and system (3.2) respectively. $U(t, x, y)=\left(\left(u_{1}(t), u_{2}(t), u_{3}(t), u_{4}(t)\right)^{T}\right.$ is the controller.

If $\alpha_{i}=0.98,(i=1,2,3,4), a=35, b=3, c=12, h=7, r=0.5$, then the diagram of the attractors of system (3.1) can be seen in (Figure 5).
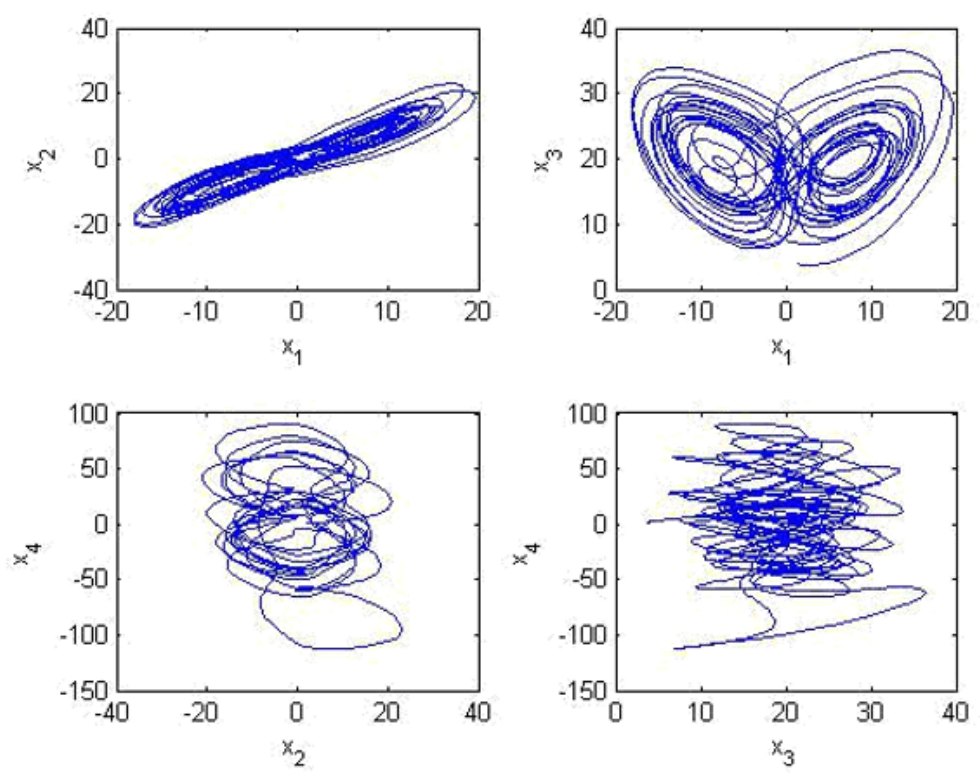

Figure 5: Diagram of the attractors indicating memory.

\section{Neurotransmitters signals Transportation}

Neurotransmitters are chemical agents secreted at the end of axons of nerve cells that diffuse across the synaptic gap and transmit information to adjoining cells such as neurons, muscle cells, and glands, by altering their electrical state or activity. There are many neurotransmitters with a variety of structures and functions.

In order to identify the neuronal functions in sleep and memory consolidation process shown above, the sleeping time step is taken as $\mathrm{h}=0.0025 \mathrm{~s}$, and
$\mathrm{T}=30 \mathrm{~s}, \alpha_{\mathrm{i}}=0.98, \mathrm{i}=(1,2,3,4), \beta_{\mathrm{i}}=0.96, \mathrm{i}=(5,------9), \mathrm{a}=35, \mathrm{~b}=3$, $c=12, h=7, r=0.5$,

The time taken for the simulation, and the order parameters, with the initial state value of system (3.1) is

taking system, to select the system $\mathrm{x}(0)=(2,0,1,1)$, the initial state value of system $(3.2)$ is $y(0)=(-4,-2,1,-5)$. Therefore, the sleeping process between system (3.1) and system (3.2) is shown in the following (Figure 6).
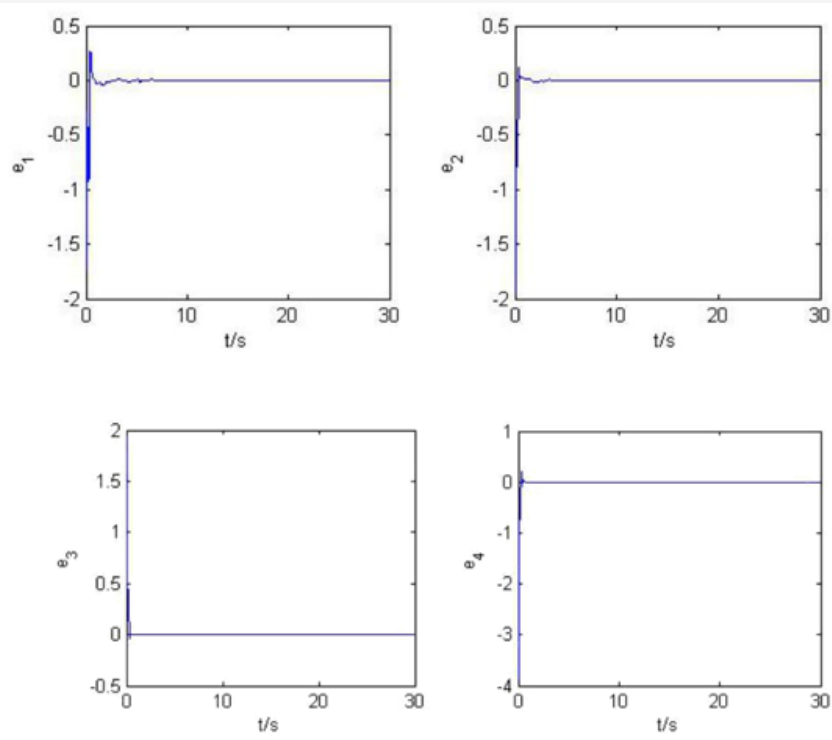

Figure 6: Modifiable structures error $\mathrm{e}_{1}, \mathrm{e}_{2}, \mathrm{e}_{3}, \mathrm{e}_{4}$ curve between system (3.1) and system (3.2). 
According to the definition of neurotransmitters signals transportation, suppose that the neurotransmitters signals transportation is $\mathrm{e}=\mathrm{x}+\mathrm{y}$. If for any $\mathrm{x}(0), \mathrm{y}(0)$ satisfy the condition $\lim _{t \rightarrow \infty}\|e\|=\lim _{t \rightarrow \infty}\|x(t)+y(t)\|=0$, then we say that system (3.1) and system (3.2) achieve modifiable structures.

$$
\left\{\begin{array}{c}
u_{1}(t)=-D_{t}^{\beta_{1}} x_{1}-D_{t}^{\alpha_{1}} x_{1}-\left(\widehat{\alpha}\left(y_{2}-y_{1}\right)+y_{4}\right)+\widehat{\alpha}\left(x_{2}-x_{1}\right)+x_{4}-k_{1} e_{1} \\
u_{2}(t)=-D_{t}^{\beta_{2}} x_{2}-D_{t}^{\alpha_{2}} x_{2}-\left(\widehat{h}\left(y_{1}-y_{1} y_{3}+\widehat{c} y_{2}\right)\right)+\widehat{h} x_{1}-x_{1} x_{3}+\widehat{c} x_{2}-k_{2} e_{2} \\
u_{3}(t)=-D_{t}^{\beta_{3}} x_{2}-D_{t}^{\alpha_{3}} x_{2}-\left(y_{1} y_{2}-\widehat{b} y_{3}\right)+x_{1} x_{2}+\widehat{b} x_{3}-k_{3} e_{3} \\
u_{4}(t)=-D_{t}^{\beta_{4}} x_{2}-D_{t}^{\alpha_{4}} x_{2}-\left(y_{2} y_{3}-\widehat{r} y_{4}\right)+x_{2} x_{3}+\widehat{r} x_{3}-k_{4} e_{4}
\end{array}\right.
$$

On the basis of adaptive control methods, we can give the virtual neurotransmitter by serotonin and acetylcholine systems in central nervous system involving sleep and memory:

where $\mathrm{e}_{1}=\mathrm{x}_{1}+\mathrm{y}_{1}, \mathrm{e}_{2}=\mathrm{x}_{2}+\mathrm{y}_{2}, \mathrm{e}_{3}=\mathrm{x}_{3}+\mathrm{y}_{3}, \mathrm{e}_{4}=\mathrm{x}_{4}+\mathrm{y}_{4}, \mathrm{k}_{\mathrm{i}}>0,(\mathrm{i}=1,2,3$, 4). If $t \rightarrow \infty$, then $\|e\|=0$, and system (3.1) and system (3.2) achieve modifiable structures indicating memory process.

If we put (4.1) and system (3.1) to system (3.2), then the following error equations can be obtained between the groups for some fractional differential equations:

$$
\left\{\begin{array}{c}
D_{t}^{\beta_{1}} e_{1}=-e_{1}\left(x_{2}-x_{1}\right)-k_{1} e_{1} \\
D_{t}^{\beta_{2}} e_{2}=-e_{d} x_{1}-e_{c} x_{2}-k_{2} e_{2} \\
D_{t}^{\beta_{3}} e_{3}=e_{b} x_{3}-k_{3} e_{3} \\
D_{t}^{\beta_{4}} e_{4}=-e_{r} x_{4}-k_{4} e_{4}
\end{array}\right.
$$

where $e_{a}=a-\hat{a}, e_{b}=b-\hat{b}, e_{c}=c-\hat{c}, e_{h}=h-\hat{h}, e_{r}=r-\hat{r}$ are the parameter estimation errors.

Next, according to (4.2), we design the adaptive update law for each parameter estimation error:

$$
\left\{\begin{array}{l}
D_{t}^{\beta_{5}} e_{a}=\left(x_{1}-x_{2}\right) e_{1} \\
D_{t}^{\beta_{6}} e_{b}=-x_{3} e_{3} \\
D_{t}^{\beta_{7}} e_{c}=x_{2} e_{2} \\
D_{t}^{\beta_{8}} e_{h}=x_{1} e_{2} \\
D_{t}^{\beta_{9}} e_{r}=x_{4} e_{4}
\end{array}\right.
$$

where $0<i<1$, $(i=5,6,7,8,9)$.

According to $e_{a}=a-\hat{a}, e_{b}=b-\widehat{b}, e_{c}=c-\hat{c}, e_{h}=h-\widehat{h}, e_{r}=r-\widehat{r}$ and (4.3), we can get the parameters of the adaptive control law:

$$
\left\{\begin{array}{l}
D_{t}^{\beta_{5}} e_{a}=\left(x_{1}-x_{2}\right) e_{1} \\
D_{t}^{\beta_{6}} e_{b}=-x_{3} e_{3} \\
D_{t}^{\beta_{7}} e_{c}=x_{2} e_{2} \\
D_{t}^{\beta_{8}} e_{h}=x_{1} e_{2} \\
D_{t}^{\beta_{9}} e_{r}=x_{4} e_{4}
\end{array}\right.
$$

According to (4.2) and (4.3), we get the total error of the system: $D_{t}^{\beta} E$
Where

$$
\begin{aligned}
D_{t}^{\beta} E & =\left(D_{t}^{\beta_{1}} e_{1}, D_{t}^{\beta_{2}} e_{2}, D_{t}^{\beta_{3}} e_{3}, D_{t}^{\beta_{4}} e_{4}, D_{t}^{\beta_{5}} e_{a}, D_{t}^{\beta_{6}} e_{b}, D_{t}^{\beta_{7}} e_{c}, D_{t}^{\beta_{8}} e_{h}, D_{t}^{\beta_{9}} e_{r}\right)^{T} \\
E & =\left(e_{1}, e_{2}, e_{3}, e_{4}, e_{5}, e_{a}, e_{b}, e_{h}, e_{r}\right)^{T}, 0<\beta_{\mathrm{i}}<1,(\mathrm{i}=---------9) .
\end{aligned}
$$

Then we consider Eq. (4.5), and expand the formula, we obtain:

$D_{t}^{\beta}\left(\begin{array}{l}e_{1} \\ e_{2} \\ e_{3} \\ e_{4} \\ e_{a} \\ e_{b} \\ e_{c} \\ e_{h} \\ e_{r}\end{array}\right)=A E=\left(\begin{array}{lllllllll}-k_{1} & 0 & 0 & 0 & -\left(x_{2}-x_{1}\right) & 0 & 0 & 0 & 0 \\ 0 & -k_{2} & 0 & 0 & 0 & 0 & -x_{2} & -x_{1} & 0 \\ 0 & 0 & -k_{3} & 0 & 0 & x_{3} & 0 & 0 & 0 \\ 0 & 0 & 0 & -k_{4} & 0 & 0 & 0 & 0 & -x_{4} \\ x_{2}-x_{1} & 0 & 0 & 0 & 0 & 0 & 0 & 0 & 0 \\ 0 & 0 & -x_{3} & 0 & 0 & 0 & 0 & 0 & 0 \\ 0 & x_{2} & 0 & 0 & 0 & 0 & 0 & 0 & 0 \\ 0 & x_{1} & 0 & 0 & 0 & 0 & 0 & 0 & 0 \\ 0 & 0 & 0 & x_{4} & 0 & 0 & 0 & 0 & 0\end{array}\right)$

Setting $\mathrm{P}=\mathrm{E}_{9}$. Then we obtain the following result:

$$
\begin{aligned}
& \mathrm{AP}=\mathrm{PA}^{\mathrm{T}} \\
& =\mathrm{A}+\mathrm{A}^{\mathrm{T}}=-\mathrm{Q} \\
& \qquad\left(\begin{array}{lllllllll}
-2 k_{1} & 0 & 0 & 0 & 0 & 0 & 0 & 0 & 0 \\
0 & -2 k_{2} & 0 & 0 & 0 & 0 & 0 & 0 & 0 \\
0 & 0 & -2 k_{3} & 0 & 0 & 0 & 0 & 0 & 0 \\
0 & 0 & 0 & -2 k_{4} & 0 & 0 & 0 & 0 & 0 \\
0 & 0 & 0 & 0 & 0 & 0 & 0 & 0 & 0 \\
0 & 0 & 0 & 0 & 0 & 0 & 0 & 0 & 0 \\
0 & 0 & 0 & 0 & 0 & 0 & 0 & 0 & 0 \\
0 & 0 & 0 & 0 & 0 & 0 & 0 & 0 & 0 \\
0 & 0 & 0 & 0 & 0 & 0 & 0 & 0 & 0
\end{array}\right)
\end{aligned}
$$

where $\mathrm{k}_{\mathrm{i}}>0$, (i=1,2,3,4) $\left.\mathrm{Q}=\operatorname{diag} 2 \mathrm{k}_{1}, 2 \mathrm{k}_{2}, 2 \mathrm{k}_{3}, 2 \mathrm{k}_{4}, 0,0,0,0,0\right)$.

It is easy to see that $\mathrm{Q}=\operatorname{diag} 2 \mathrm{k}_{1}, 2 \mathrm{k}_{2}, 2 \mathrm{k}_{3}, 2 \mathrm{k}_{4}, 0,0,0,0,0$ is a semi-positive definite matrix. Then, the state variable of (4.5) $E=\left(e_{1}, e_{2}, e_{3}, e_{4}, e_{5}, e_{a}, e_{b}, e_{h}, e_{r}\right)^{T}$ is asymptotically stable, that is, $e_{1}, e_{2}, e_{3}, e_{4}, e_{5}, e_{a}, e_{b}, e_{h}, e_{r}$ approach zero asymptotically with time.

Therefore, we achieve the neuronal functions in sleep and memory consolidation process by a number of adaptive robust set of fractional differential equations anti-synchronization indicating memory process.

\section{Chemical and Physicael Propertis}

In this part, mainly through the mathematical method, the preliminary screening of the data in Table 1 for the chemical and physicael propertis of neuron, and respectively by MATLAB and SPSS 22 software to the data provided by principal component analysis, that can only find that the influence factors on the quality of sleep and memory process standard, but can't find out what factors. Then we use the binary logistic regression model to process the data (Table 1\&2).

First, we extract the data from the above Table 2 to make the $12 * 7$ Table, and then use the principal component analysis method in MATLAB software (The code is shown in the last Annex 1 of this 
article). We find out that the most influential factors are Formal Charge, Heavy Atom Count, Defined Atom Stereocenter Count. Finally, we analyze the data in Table 2, draw the broken line diagram
(The code is shown in the last Annex 2 of this article), which is the following Figure 7, and we find out that the fifth neurotransmitters GABA is the most prominent one [19-62] (Figure 7).

Table 1: Chemical and physical properties of the neuron.

\begin{tabular}{|c|c|c|c|c|c|c|c|}
\hline \multirow{2}{*}{$\begin{array}{l}\text { Property } \\
\text { Name }\end{array}$} & \multicolumn{7}{|c|}{ Property Value } \\
\hline & L-Adrenaline & $\begin{array}{c}\text { Nor Adrenaline } \\
\text { (Norepinephrine) }\end{array}$ & Dopamine & Serotonin & GABA & Acetylcholine & Glutamate \\
\hline $\begin{array}{l}\text { Molecular } \\
\text { Weight }\end{array}$ & $183.207 \mathrm{~g} / \mathrm{mol}$ & $169.18 \mathrm{~g} / \mathrm{mol}$ & $153.181 \mathrm{~g} / \mathrm{mol}$ & $176.219 \mathrm{~g} / \mathrm{mol}$ & $103.121 \mathrm{~g} / \mathrm{mol}$ & $146.21 \mathrm{~g} / \mathrm{mol}$ & $147.13 \mathrm{~g} / \mathrm{mol}$ \\
\hline $\begin{array}{l}\text { Hydrogen Bond } \\
\text { Donor }\end{array}$ & 4 & 4 & 3 & 3 & 2 & 0 & 3 \\
\hline $\begin{array}{l}\text { Hydrogen Bond } \\
\text { Acceptor Count }\end{array}$ & 4 & 4 & 3 & 2 & 3 & 2 & 5 \\
\hline $\begin{array}{l}\text { Rotatable Bond } \\
\text { Count }\end{array}$ & 3 & 2 & 2 & 2 & 3 & 4 & 4 \\
\hline Complexity & 154 & 142 & 119 & 174 & 62.7 & 115 & 145 \\
\hline
\end{tabular}

\begin{tabular}{|c|c|c|c|c|c|c|c|}
\hline $\begin{array}{l}\text { Topological Polar } \\
\text { Surface Area }\end{array}$ & $72.7 \mathrm{~A}^{\wedge} 2$ & $86.7 \mathrm{~A}^{\wedge} 2$ & $66.5 \mathrm{~A}^{\wedge} 2$ & $62 \mathrm{~A}^{\wedge} 2$ & $63.3 \mathrm{~A}^{\wedge} 2$ & $26.3 \mathrm{~A}^{\wedge} 2$ & $101 \mathrm{~A}^{\wedge} 2$ \\
\hline Monoisotopic Mass & $\begin{array}{l}183.09 \mathrm{~g} / \\
\mathrm{mol}\end{array}$ & $\begin{array}{l}169.074 \mathrm{~g} / \\
\mathrm{mol}\end{array}$ & $\begin{array}{l}153.079 \mathrm{~g} / \\
\mathrm{mol}\end{array}$ & $\begin{array}{l}176.095 \mathrm{~g} / \\
\mathrm{mol}\end{array}$ & $\begin{array}{l}103.063 \mathrm{~g} / \\
\mathrm{mol}\end{array}$ & $\begin{array}{l}146.118 \mathrm{~g} / \\
\mathrm{mol}\end{array}$ & $\begin{array}{l}147.053 \mathrm{~g} / \\
\mathrm{mol}\end{array}$ \\
\hline Exact Mass & $\begin{array}{c}183.09 \mathrm{~g} / \\
\text { mol }\end{array}$ & $\begin{array}{l}169.074 \mathrm{~g} / \\
\mathrm{mol}\end{array}$ & $\begin{array}{c}153.079 \mathrm{~g} / \\
\mathrm{mol}\end{array}$ & $\begin{array}{l}176.095 \mathrm{~g} / \\
\mathrm{mol}\end{array}$ & $\begin{array}{l}103.063 \mathrm{~g} / \\
\mathrm{mol}\end{array}$ & $\begin{array}{l}146.118 \mathrm{~g} / \\
\mathrm{mol}\end{array}$ & $\begin{array}{l}147.053 \mathrm{~g} / \\
\mathrm{mol}\end{array}$ \\
\hline $\mathrm{XLogP3}$ & -1.4 & -1.2 & -1 & 0.2 & -3.2 & 0.2 & -3.7 \\
\hline $\begin{array}{l}\text { Compound Is } \\
\text { Canonicalized }\end{array}$ & TRUE & TRUE & TRUE & TRUE & TRUE & TRUE & TRUE \\
\hline Formal Charge & 0 & 0 & 0 & 0 & 0 & 1 & 0 \\
\hline Heavy Atom Count & 13 & 12 & 11 & 13 & 7 & 10 & 10 \\
\hline $\begin{array}{c}\text { Defined Atom } \\
\text { Stereocenter Count }\end{array}$ & 1 & 1 & 0 & 0 & 0 & 0 & 1 \\
\hline $\begin{array}{r}\text { Undefined Atom } \\
\text { Stereocenter Count }\end{array}$ & 0 & 0 & 0 & 0 & 0 & 0 & 0 \\
\hline $\begin{array}{c}\text { Defined Bond } \\
\text { Stereocenter Count }\end{array}$ & 0 & 0 & 0 & 0 & 0 & 0 & 0 \\
\hline $\begin{array}{r}\text { Undefined Bond } \\
\text { Stereocenter Count }\end{array}$ & 0 & 0 & 0 & 0 & 0 & 0 & 0 \\
\hline $\begin{array}{l}\text { Isotope Atom } \\
\text { Count }\end{array}$ & 0 & 0 & 0 & 0 & 0 & 0 & 0 \\
\hline $\begin{array}{l}\text { Covalently-Bonded } \\
\text { Unit Count }\end{array}$ & 1 & 1 & 1 & 1 & 1 & 1 & 1 \\
\hline
\end{tabular}

Table 2: The compression of the chemical and physicael propertis of the neuron.

\begin{tabular}{|c|c|c|c|c|c|c|c|}
\hline Property Name & L-Adrenaline & $\begin{array}{l}\text { Nor Adrenaline } \\
\text { (Norepinephrine) }\end{array}$ & Dopamine & Serotonin & GABA & Acetylcholine & Glutamate \\
\hline $\begin{array}{l}\text { Molecular } \\
\text { Weight }\end{array}$ & 183.207 & 169.18 & 153.181 & 176.219 & 103.121 & 146.21 & 147.13 \\
\hline $\begin{array}{l}\text { Hydrogen Bond } \\
\text { Donor Count }\end{array}$ & 4 & 4 & 3 & 3 & 2 & 0 & 3 \\
\hline $\begin{array}{l}\text { Hydrogen Bond } \\
\text { Acceptor Count }\end{array}$ & 4 & 4 & 3 & 2 & 3 & 2 & 5 \\
\hline $\begin{array}{l}\text { Rotatable Bond } \\
\text { Count }\end{array}$ & 3 & 2 & 2 & 2 & 3 & 4 & 4 \\
\hline Complexity & 154 & 142 & 119 & 174 & 62.7 & 115 & 145 \\
\hline $\begin{array}{c}\text { Topological } \\
\text { Polar Surface } \\
\text { Area }\end{array}$ & 72.7 & 86.7 & 66.5 & 62 & 63.3 & 26.3 & 101 \\
\hline $\begin{array}{l}\text { Monoisotopic } \\
\text { Mass }\end{array}$ & 183.09 & 169.074 & 153.079 & 176.095 & 103.063 & 146.118 & 147.053 \\
\hline
\end{tabular}




\begin{tabular}{|c|c|c|c|c|c|c|c|}
\hline Exact Mass & 183.09 & 169.074 & 153.079 & 176.095 & 103.063 & 146.118 & 147.053 \\
\hline XLogP3 & -1.4 & -1.2 & -1 & 0.2 & -3.2 & 0.2 & -3.7 \\
\hline Formal Charge & 0 & 0 & 0 & 0 & 0 & 1 \\
\hline $\begin{array}{c}\text { Heavy Atom } \\
\text { Count }\end{array}$ & 13 & 12 & 11 & 13 & 7 & 10 & 10 \\
\hline $\begin{array}{c}\text { Defined Atom } \\
\text { Stereocenter } \\
\text { Count }\end{array}$ & 1 & 1 & 0 & 0 & 0 & 0 \\
\hline
\end{tabular}

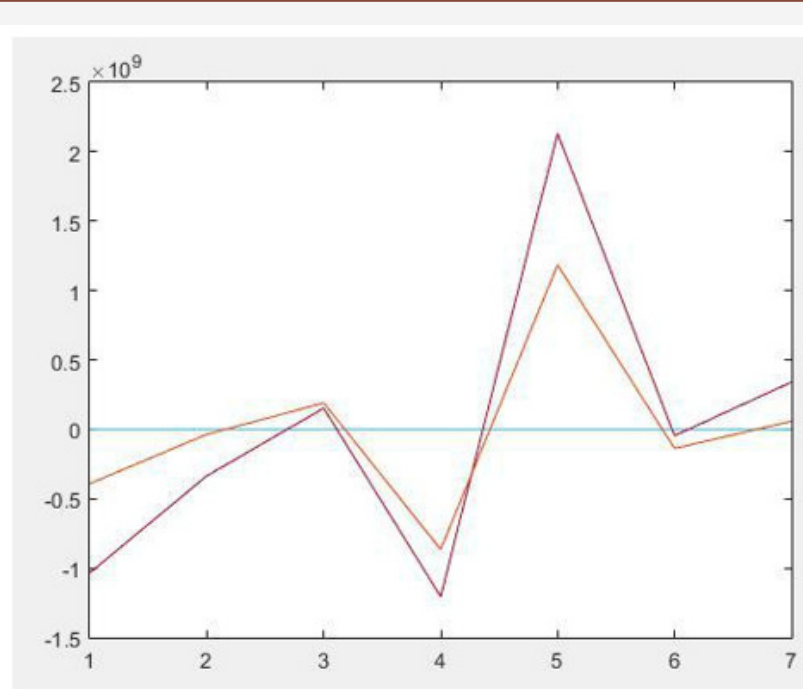

Figure 7: Broken line diagram of (Table 2).

For $X \neq 0$ and natural number $\mathrm{n}$, taking the logarithmically differential into consideration yields

$\left[f_{\alpha, \beta}(x)\right]^{(n)}=\frac{1}{x^{n+1}}\left[\sum_{k=0}^{n}(-1)^{k} \frac{n ! x^{n-k} \varphi^{(n-k-1)}(x+y)}{(n-k) !}-(-1)^{n} n ! \ln \Gamma(y)-\alpha(-1)^{(n-1)}(n-1) ! x\right]$

where $\psi^{(-1)}(x+y)$ and $\psi^{(0)}(x+y)$ stand for $\ln \Gamma(\mathrm{x}+\mathrm{y})$ and $\psi(x+y)$ respectively.

Furthermore, differentiating $x^{n+1}\left[f_{\alpha, \beta}(x)\right]^{(n)}$ directly gives

$\left\{x^{n+1}\left[f_{\alpha, \beta}(x)\right]^{(n)}\right\}=(-1)^{n-1} x^{n}\left[(-1)^{n+1} \varphi^{(n)}(x+y)-\frac{\alpha(n-1) !}{x^{n}}\right]$

Making use of (2.11) and (2.13) shows that for all $n \in N$ and any fixed $y>0$, the double inequality

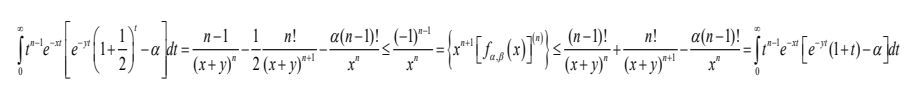

holds for all $x \in(-y, \infty) \backslash\{0\}$ and $\alpha \in(-\infty, \infty)$

For any fixed $y \in(0, \infty)$, let $\mathrm{u}(\mathrm{t})$ and $\mathrm{v}(\mathrm{t})$ be defined on $(-\infty, \infty)$ by $u(t)=e^{-y t}\left(1+\frac{1}{2}\right)^{t}$ and $\mathrm{v}(\mathrm{t})=e^{-y t}(1+\mathrm{t})$ respectively.

Differentiating $u(t)$ and $v(t)$ directly, we obtain

$$
\begin{aligned}
& u(t)=e^{-y t}\left(\frac{1}{2}-y-\frac{1}{2} y t\right) . \\
& v(t)=e^{-y t}(1-y-y t)
\end{aligned}
$$

Therefore, for given $y \in(-\infty, \infty)$, we have

$$
u(t)=\left\{\begin{array}{l}
>0, t<1 / y-2 \\
<0, t>1 / y-2
\end{array},\right.
$$

and

$$
v(t)=\left\{\begin{array}{l}
>0, t<1 / y-2 \\
<0, t>1 / y-2
\end{array},\right.
$$

From (5.6) and (5.7), we conclude that for all $t>0$ we obtain $\mathrm{u}(\mathrm{t})>0$,

and

$$
v(t)=\left\{\begin{array}{l}
<1, y \geq 2 \\
\leq e^{-(1-y)} / y, 0<y<1
\end{array}\right.
$$

From (5.3) and (5.8) -(5.9), it is easy to see that

$$
\frac{(-1)^{n+1}}{x^{n}}\left\{x^{n+1}\left[f_{\alpha, \beta}(x)\right]^{(n)}\right\}=\left\{\begin{array}{l}
>0, \text { if } \alpha \leq 0 \text { forfixed } y>0 \\
<0, \text { f } \alpha \geq 0 \text { forfixed } y \geq 1 \\
<0, \text { f } \alpha \geq e^{-(1-y)} / \text { yforfixedo }<y<1
\end{array}\right.
$$

For all $n \in N \quad x \in(-y, \infty) \backslash\{0\}$

On the one hand, if $x \in(0, \infty)$ then the inequalities (5.10) can be equivalently changed into

$$
x^{2 k+1}\left[f_{\alpha, \beta}(x)\right]^{(2 k-1)}=\left\{\begin{array}{l}
>0, \text { if } \alpha \leq 0 \text { forfixed } y>0 \\
<0, \text { f } \alpha \geq 0 \text { forfixedy } \geq 1 \\
<0, \text { f } \alpha \geq e^{-(1-y)} / \text { yforfixedo }<y<1
\end{array}\right.
$$

and

$$
x^{2 k}\left[f_{\alpha, \beta}(x)\right]^{(2 k-1)}=\left\{\begin{array}{l}
>0, \text { if } \alpha \leq 0 \text { forfixed } y>0 \\
<0, \text { f } \alpha \geq 0 \text { forfixedy } \geq 1 \\
<0, f \alpha \geq e^{-(1-y)} / \text { yforfixedo }<y<1
\end{array}\right.
$$

for $k \in N$

From (5.1), then simple computation shows that

$$
\lim _{x \rightarrow 0} x^{n+1}\left[f_{\alpha, \beta}(x)\right]^{(n)}
$$

for all $n \in N$ and any given $y \in(0, \infty)$. As a result,

$$
x^{2 k+1}\left[f_{\alpha, \beta}(x)\right]^{(2 k)}=\left\{\begin{array}{l}
>0, \text { if } \alpha \leq 0 \text { forfixed } y>0 \\
<0, \text { f } \alpha \geq 0 \text { forfixed } y \geq 1 \\
<0, \text { f } \alpha \geq e^{-(1-y)} / \text { yforfixedo }<y<1
\end{array}\right.
$$




$$
x^{2 k}\left[f_{\alpha, \beta}(x)\right]^{(2 k+1)}=\left\{\begin{array}{l}
>0, \text { if } \alpha \leq 0 \text { forfixedy }>0 \\
<0, \text { f } \alpha \geq 0 \text { forfixed } y \geq 1 \\
<0, f \alpha \geq e^{-(1-y)} / y \text { forfixedo }<y<1
\end{array}\right.
$$

for all $k \in N$ and all $\mathrm{x}>0$.

Therefore, (5.14) and (5.15) imply

$$
\begin{aligned}
& x^{2 k+1}\left[f_{\alpha, \beta}(x)\right]^{(2 k-1)}=\left\{\begin{array}{l}
>0, \text { if } \alpha \leq 0 \text { forfixedy }>0 \\
<0, \text { f } \alpha \geq 0 \text { forfixedy } \geq 1 \\
<0, \text { f } \alpha \geq e^{-(1-y)} / \text { yforfixedo }<y<1
\end{array}\right. \\
& (-1)^{n}\left[f_{\alpha, \beta}(x)\right]^{(n)}=\left\{\begin{array}{l}
>0, \text { if } \alpha \leq 0 \text { forfixedy }>0 \\
<0, \text { f } \alpha \geq 0 \text { forfixedy } \geq 1 \\
<0, \text { f } \alpha \geq e^{-(1-y)} / \text { yforfixedo }<y<1
\end{array}\right.
\end{aligned}
$$

for all $n \in N$ and all $\mathrm{x}>0$.

Hence, if either $\alpha \geq e^{-(1-y)} / y \quad$ for given $0<\mathrm{y}<1$ or $\alpha \geq 1$ for given $y \geq 1$, the function (1.13) is strictly

logarithmically completely monotonic with respect to $\mathrm{x}$ on

$$
\left\{x^{n+1}\left[f_{\alpha, \beta}(x)^{n}\right]\right\}=\left\{\begin{array}{l}
>0, \text { if } \alpha \leq 0 \text { forfixed } y>0 \\
<0, \text { f } \alpha \geq 0 \text { forfixed } y \geq 1 \\
<0, \text { f } \alpha \geq e^{-(1-y)} / \text { yforfixedo }<y<1
\end{array}\right.
$$

for $n \in N$

In view of (5.13), we can conclude that

$$
\left\{(x+y)^{n+1}\left[f_{\alpha, \beta}(x)^{n}\right]\right\}=\left\{\begin{array}{l}
>0, \text { if } \alpha \leq 0 \text { forfixed } y>0 \\
<0, f \alpha \geq 0 \text { forfixed } y \geq 1 \\
<0, f \alpha \geq e^{-(1-y)} / \text { yforfixedo }<y<1
\end{array}\right.
$$

for $n \in N$ It is obvious that (5.18) is equivalent to that (5.14) and (5.15) hold for any given $y>0$

and $x \in(-y, 0)$.Therefore, it is easy to prove similarly that (5.16) is also valid on $x \in(-y, 0)$ for any given

$$
\text { y>0 and all } n \in N
$$

As a result, we can conclude that nervousness has the strongest influence on sleep and memory quality.

\section{Conclusion}

SWS and REM sleep complement each other to optimize memory integration. In the SWS process in which slow oscillations induce a broad synchronization of neuronal activity, active system consolidation combines newly encoded memory with preexisting long-term memory to induce conformational changes in their respective expressions. System integration (priority affects explicit coding of behavior-related information) synergizes with global synaptic downscaling, primarily to rule out saturation of synaptic networks. Subsequent REM sleep, characterized by desynchronization of the neural network, may reflect the detachment of the memory system-possibly stabilizing the transformed memory by consolidating undisturbed synapses.

Sleep deprivation suppressed activation of the kinase complex mTORC1 which leads to a decrease in phosphorylation of 4EBP2, leading to disruption of protein translation, reduced neuroplasticity, and ultimately cognitive impairment. Restoring protein synthesis by increasing the amount of phosphorylated 4EBP2 protein in the hippocampus, a function normally performed by mTORC1 can compensate the memory impairment caused by sleep deprivation. Also, some alternative mechanisms may actuate as well in the protein synthesis reduction which needs a further studying.

The development of neurotransmitters and its complex functions during sleep and memory process are influenced by numerous factors. In this study, some mathematical speculations have been proposed on the basis of structural and functional characteristics of virtual neuron (especially the physiological phenomena of human beings) with a molecular docking and biomathematical approach to formulate some speculations to the consolidation of sleep and memory process. This could pave a way to formulate more mathematical speculations related with neuron, and finally these data and approaches will be useful for constructing virtual neuron with the help of biomathematics.

\section{Conflict of Interest}

We have no conflict of interests to disclose and the manuscript has been read and approved by all named authors.

\section{Acknowledgment}

We would like to express my gratitude to all those who helped us during the writing of this article.

\section{References}

1. Sweatt JD, Hawkins KE (2016) The molecular neurobiology of the sleepdeprived, fuzzy brain. Science Signaling 9(425): 1-2.

2. Tudor JC, Davis EJ, Peixoto L, Wimmer ME, van Tilborg E, et al. (2016) Sleep deprivation impairs memory by attenuating mTORC1-dependent protein synthesis. Science Signaling 9(425) :1-19.

3. Wagner U, Gais S, Born J (2001) Emotional memory formation is enhanced across sleep intervals with high amounts of rapid eye movement sleep. Learning \& Memory 8 (2): 112.

4. Nishida M1, Pearsall J, Buckner RL, Walker MP (2008) REM sleep, prefrontal theta, and the consolidation of human emotional memory. Cerebral Cortex 19(5) :1158-1166.

5. Smith C (2003) The REM sleep window and memory processing in Sleep and brain plasticity. New York: Oxford University Press

6. Maquet $P$ (2001) The role of sleep in learning and memory. Science 294(5544): 1048-1052.

7. Rasch B, Büchel C, Gais S, Born J (2007) Odor cues during slow-wave sleep prompt declarative memory consolidation. Science, 315 (5817): 1426-1429.

8. Gais S, Plihal W, Wagner U, Born J (2000) Early sleep triggers memory for early visual discrimination skills. Nature Neuroscience 3(12): 13351339.

9. Giuditta A, Ambrosini MV, Montagnese P, Mandile P, Cotugno M, et al. (1995) The sequential hypothesis of the function of sleep. Behavioral Brain Research 69(1-2): 157-166.

10. Frankland PW, Bontempi B (2005) The organization of recent and remote memories. Nature Reviews Neuroscience 6(2): 119-130.

11. Tononi G, Cirelli C (2006) Sleep function and synaptic homeostasis. Sleep Medicine Reviews 10 (1): 49-62.

12. Marshall L, Born J (2007) The contribution of sleep to hippocampusdependent memory consolidation. Trends in Cognitive Science 11(10): 442-450. 
13. Vyazovskiy VV, Cirelli C, Pfister Genskow M, Faraguna U, Tononi G et al. (2008) Molecular and electrophysiological evidence for net synaptic potentiation in wake and depression in sleep. Nature Neuroscience 11(2): 200-208.

14. Dash MB, Douglas CL, Vyazovskiy VV, Cirelli C, Tononi G, et al. (2009) Long-term homeostasis of extracellular glutamate in the rat cerebral cortex across sleep and waking states. Journal of Neuroscience 29 (3): 620-629.

15. Marion Kuhn, Elias Wolf, Jonathan G. Maier, Florian Mainberger, et al (2016) Bernd Feige Sleep recalibrates homeostatic and associative synaptic plasticity in the human cortex. Nature Communication 7: 12455.

16. Vecsey CG, Peixoto L, Choi JH, Wimmer M, Jaganath D, et al. (2012) Genomic analysis of sleep deprivation reveals translational regulation in the hippocampus. Physiological Genomics 44 (20): 981-991.

17. Steven E Hyman (2005) Neurotransmitters. Current Biology 15(5): $154-$ 158.

18. Masland RH (2004) Neuronal cell types. Current Biology 14(13) : 497500 .

19. Eric J Nestler, Steven E Hyman, David M Holtzman, Robert C Malenka, (2001) Molecular Neuropharmacology: Foundation for Clinical Neuroscience. New York: McGraw Hill.

20. Pestana M, Jardim H, Correia F, Vieira Coelho MA, Soares-da-Silva P (2001) Renal dopaminergic mechanisms in renal parenchymal diseases and hypertension. Nephrol Dial Transplant 16(1) : 53-59.

21. Marko AM, Gerrard JW, Buchan DJ (1960) Glutamic acid derivatives in adult celiac disease. II. Urinary total glutamic acid excretion. Canadian Medical Association Journal 83:1324-1325.

22. Bélanger R, Chandramohan N, Misbin R, Rivlin RS (1972) Tyrosine and glutamic acid in plasma and urine of patients with altered thyroid function. Metabolism 21(9): 855-865.

23. Ragginer C, Lechner A, Bernecker C, Horejsi R, Möller R (2012) Reduced urinary glutamate levels are associated with the frequency of migraine attacks in females. European Journal Neurology 19(8): 1146-1150.

24. Tiffany Field, Miguel Diego, Maria Hernandez-Reif, Barbara Figueiredo, Osvelia Deeds, et al. (2010) Comorbid depression and anxiety effects on pregnancy and neonatal outcome. Infant Behavior Development 33(1): 23-29.

25. Ghaddar A, Omar KH, Dokmak M, Kansour NA, Jbara Z, et al. (2014) Work-related stress and urinary catecholamines among laboratory technicians. Journal of Occupational Health 55 (5): 398-404.

26. Liu L, Li Q Li N, Ling J, Liu R, et al, (2011) Simultaneous determination of catecholamines and their metabolites related to Alzheimer's disease in human urine. Journal Separation Science 34 (10): 1198-1204.

27. Paine NJ, Watkins LL, Blumenthal JA, Kuhn CM, Sherwood A (2015) Association of depressive and anxiety symptoms with 24-hour urinary catecholamines in individuals with untreated high blood pressure. Psychosomatic Medicine 77 (2):136-144.

28. Hughes JW, Watkins L, Blumenthal JA, Kuhn C, Sherwood A (2004) Depression and anxiety symptoms are related to increased 24-hour urinary norepinephrine excretion among healthy middle-aged women. Journal of Psychosomatic Research 57(4): 353-358.

29. Koslow SH, Maas JW, Bowden CL, Davis JM, Hanin I et al. (1983) CSF and urinary biogenic amines and metabolites in depression and mania. A controlled, univariate analysis. Archives General Psychiatry 40(9): 9991010.

30. Nicholson Guthrie CS, Guthrie GD, Sutton GP, Baenziger JC (2001) Urine GABA levels in ovarian cancer patients: elevated GABA in malignancy. Cancer Letters 162 (1): 27-30.

31. Nichkova MI, Huisman H, Wynveen PM, Marc DT, Olson KL, et al. (2012) Evaluation of a novel ELISA for serotonin: urinary serotonin as a potential biomarker for depression. Analytical \& Bioanalytical Chemistry 402(4): 1593-6000.
32. Aruoma OI, Bahorun T, Jen LS (2003) Neuroprotection by bioactive components in medicinal and food plant extracts. Mutation Research 544 (2-3): 203-215.

33. Zhao B, Diraviyam T, Zhang XY (2015) A bio-mathematical approach: Speculations to construct virtualplacenta. Applied Mathematics and Computation 256: 344-351.

34. Cumpson P, Sano, Naoko (2013) Stability of reference masses V: UV/ ozone treatment of gold and platinum surfaces. Metrologia 50 (1): 2736.

35. Ganesh S, Vennila JJ, Mercy AA (2013) Effects of Phytochemicals extracted from Acanthus Ilicifolius against Staphylococcus aureus: An In-silico approach. American Journal of Drug Discovery and Development 3(4): 293-297.

36. Wang T, Zhang X, Xie W (2012) Cistanche deserticola Y. C. Ma, "Desert Ginseng": A Review. TheAmerican Journal of Chinese Medicine 40(6): 1123-1141.

37. Meraj K, Mahto MK, Christina NB, Desai N, Shahbazi S, et al. (2012) Molecular modeling, docking and ADMET studies towards development of novel Disopyramide analogs for potential inhibition of human voltage gated sodium channel proteins. Bioinformation 8 (23): 1139-1146.

38. William JE (2007) Computational Models for ADME. Annual Reports in Medicinal Chemistry $42: 449-467$.

39. Hélène Pollard, Jean Charles Schwartz (1987) Histamine neuronal pathways and their functions. Trends in Neurosciences 10(2): 86-89.

40. Schmidt JT (1979) The laminar organization of optic nerve fibers in the tectum of goldfish. Proceedings of the Royal Society of London 205(1159): 287-306.

41. Schmidt JT, Freeman JA (1980) Electrophysiologic evidence that retinotectal synaptic transmission in the goldfish is nicotinic cholinergic. Brain Research 187(1): 129-142.

42. Strange PG In Dopamine Receptors. New York: AR Liss 1987.

43. Asano T, Ui M, Ogasawara N (1985) Prevention of the Agonist Binding to y-Aminobutyric Acid B Receptors by Guanine Nucleotides and Isletactivating Protein, Pertussis Toxin, in Bovine Cerebral Cortex. Journal of Biological Chemistry 260(23) :12653-12658.

44. Monaghan DT, Cotman CW (1986) Identification and properties of N-methyl-D-aspartate receptors in rat brain synaptic plasma membranes. Proceedings of the National Academy of Sciences of the United States of America 83(19): 7533-7536.

45. Bloom FE (1979) The Neurosciences, Fourth Study Program. Cambridge: MIT Press.

46. Daniel Okoh, Oluwafisayo Owolabi, Christopher Ekechukwu, Olanike Folarin, Gila Arhiwo, et al. (2016) A regional GNSS-VTEC model over Nigeria using neural networks: A novel approach. Geodesy and Geodynamics 7(1): 19-31.

47. Shen J, Tan C, Zhang Y (2010) Discovery of Potent Ligands for Estrogen Receptor $\beta$ by Structure-Based Virtual Screening . Journal of Medicinal Chemistry 53(14): 5361-5365.

48. Xiu-ling Li, Jun-jie Wei (2013) Stability and Bifurcation Analysis in a System of Four Coupled Neurons with Multiple Delays. Acta Mathematicae Applicatae Sinica (English Series) 29(2): 425-448.

49. Chen S, Zhang XJ, Li LX, Wang Y, Zhong RJ, et al. (2015) Histone deacetylase 6 delays motor neuron degeneration by ameliorating the autophagic flux defect in a transgenic mouse model of amyotrophic lateral sclerosis. Neuroscience Bulletin 31(4): 459-468.

50. Urbanska M, Blazejczyk M, Jaworski J (2008) Molecular basis of dendritic arborization. Acta neurobiologiae experimentalis, 68 (2): 264-288.

51. Yoursefi F, Amoozandeh Z (2016) Statistical mechanics and artificial intelligence to model the thermodynamic properties of pure and mixture of ionic liquids. Chinese Journal of Chemical Engineering 24(12) :17611771.

Citation: Bin Zhao, Kuiyun Huang, Jinming Cao, Xia Jiang, Jingfeng Tang. Construction of Virtual Neuron and Consolidation of Sleep and Memory Process- A Molecular Docking and Biomathematical Approach. Arch Animal Husb \& Dairy Sci. 1(3): 2019. AAHDS.MS.ID.000512. 
52. Yoursefi F, Amoozandeh Z (2017) A new model to predict the densities of nanofluids using statistical mechanics and artificial intelligent plus principal component analysi. Chinese Journal of Chemical Engineering 25 (9): 1273-1281.

53. Yong Xie, Yan Mei Kang, Yong Liu, Ying Wu et al. (2014) Firing properties and synchronization rate in fractional-order Hindmarsh-Rose model neurons. Science China (Technological Sciences) 57(5): 914-922.

54. Zhao J, Xu H, Tian Y, Hu M, Xiao H (2013) Effect of electroacupuncture on brain-derived neurotrophic factor mRNA expression in mouse hippocampus following cerebral ischemia-reperfusion injury. Journal of Traditional Chinese Medicine 33(2): 253-257.

55. Cui HY, Feng C, Liu YJ (2013) Analysis of prediction performance in wavelet minimum complexity echo state network. The Journal of China Universities of Posts and Telecommunications 20(4): 59-66.

56. Barker JL, Mc Burney RN (1979) Phenobarbitone modulation of postsynaptic GABA receptor function on cultured mammalian neurons. Proceedings of the Royal Society of London 206(1979): 319-327.

57. Kosofsky BE, Molliver ME, Morrison JH, Foote SL (1984) The serotonin and norepinephrine innervation of primary visual cortex in the cynomolgus monkey (Macaca fascicularis). Journal of Comparative Neurology 230(2): 168-178.

58. Ramachandran VS, Cronin Golomb A, Myers JJ (1986) Perception of apparent motion by commissurotomy patients. Nature 320 (6060): 358359.

59. Brown JR, Arbuthnott GW (1983) The electrophysiology of dopamine (D2) receptors: a study of the actions of dopamine on corticostriatal transmission. Neuroscience 10(2): 349-355.

60. Moore RY, Bloom FE (1979) Central catecholamine neuron systems: anatomy and physiology of thenorepinephrine and epinephrine systems. Annual Review of Neuroscience 2: 113-168.

61. CW Cotman LL Iversen (1987). Excitatory amino acids in the brain focus on NMDA receptors. Trends in Neurosciences 10(7): 263-265.

62. Shen J, Tan C, Zhang Y (2010) Discovery of Potent Ligands for Estrogen Receptor $\beta$ by Structure-Based Virtual Screening. Journal of Medicinal Chemistry, 53 (14): 5361-5365. 